This newsletter (ISSN 1046-3410) is published by ALA's Association of Library Collections and Technical Services, Vendor-Library Relations Committee, Serials Pricing Issues Subcommittee. To subscribe via BITNET send the following oneline message to LISTSERV@UNCVX1:

SUBSCRIBE PRICES-L your_full_name

Updegrove, Daniel (UPDEGROV@EDUCOM), Muffo, John A. (IRMUFFO@VTVMI),
Dunn, John A. Jr. (DUNN@TUFTS), “Electronic Mail and Networks: New Tools for Institutional Research and Planning." July 1989, BITNET.

This is an excellent introduction to e-mail and national networks, written for the beginner. The document includes tips on e-mail etiquette and specific suggestions for getting started. To obtain the file send the message:

GET EMAILNET UPDEGR_D to LISTSERV@BITNIC

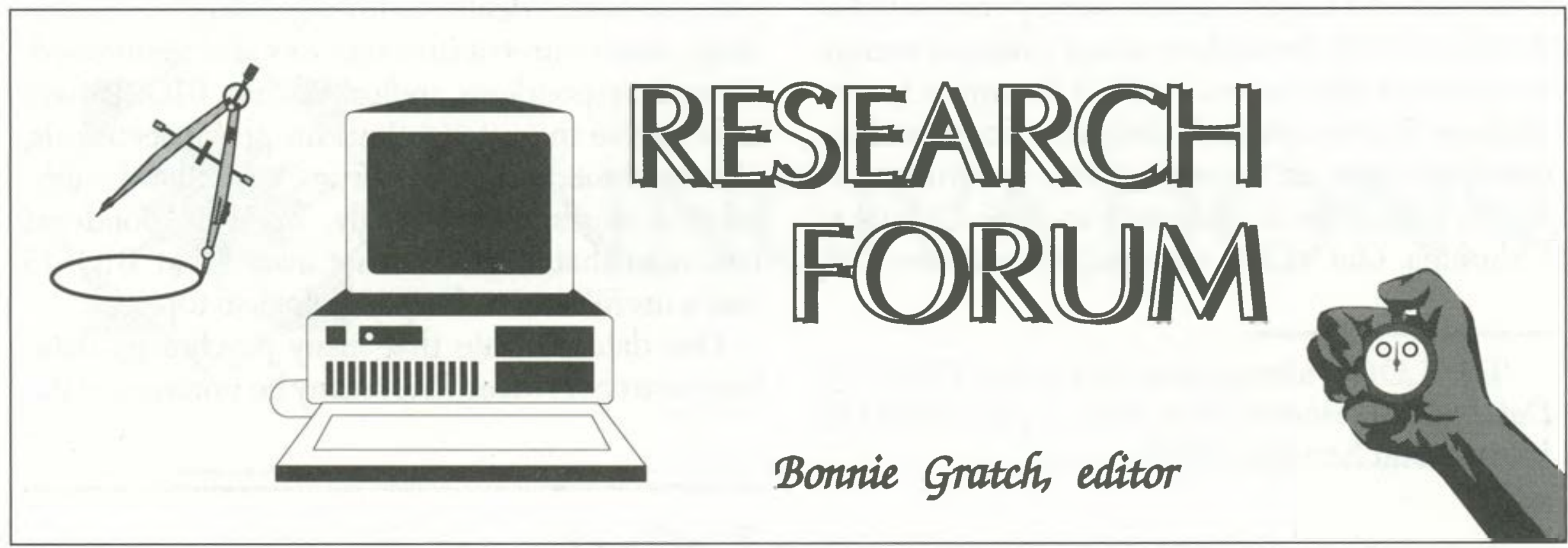

\title{
BIOSIS Previews and psychological research
}

By Bob Perdue

Science Reference Librarian

University of West Florida and Chris Piotrowski

Adjunct Professor of Psychology

University of West Florida
The literature in psychology is replete with references to the advantages of multi-database searching in conjunction with PsycINFO. ${ }^{1}$ Whereas PsycINFO and PsycALERT are the databases of choice for psychology researchers, many other files have been shown to be highly relevant for information retrieval in the behavioral sci-

${ }^{1}$ Chris Piotrowski and Bob Perdue, "Multi-Database Searching in Forensic Psychology," Forensic Reports 1 (1988): 55-63; Linda K. Lewis, "Bibliographic Computerized Searching in Psychology," Teaching of Psychology 13 (February 1986): 38-40; and Alice A. Brand, "Searching Multiple Indexes and Data Bases in the Behavioral Sciences: Which and How Many?" Behavioral and Social Sciences Librarian 1 (1979): 105-12. ences-including BIOSIS Previews. ${ }^{2}$ Although the potential usefulness of BIOSIS has been documented for the behavioral researcher, no studies have surveyed the extent of its present use in

${ }^{2}$ Bob Perdue, "BIOSIS Previews: Implications for Research on Behavioral Medicine," Medical Reference Services Quarterly 7 (1988): 57-62; Nancy G. Bruce and Ann L. Farren, "Searching BIOSIS Previews in the Health Care Setting," Medical Reference Services Quarterly 6 (1987): 17-37; Bob Perdue, "Personality Assessment Online Literature Retrieval Strategies," Forensic Reports 1 (1988): 259-66; Larry S. Perry and Richard H. Dana, "Macroconceptual Analysis of Psychological Literature: Online Computer Search Systems," Professional Psychology: Research and Practice 16 (1985): 354-62. 
research related to psychology.

The BIOSIS Previews database provides access to a wealth of behavioral literature as a result of indexing over 9,000 source journals as well as numerous monographs, books, and theses. In addition to the inclusion of many multi-disciplinary biomedical sources, more than 450 journals devoted exclusively to psychology and psychiatry are also indexed. The database now contains more than 6 million records dating back to $1969 .{ }^{3}$ Obviously, a file of this size and scope offers the psychological researcher a large potential pool of relevant scholarly information.

As part of a larger national survey conducted in the fall of 1988, the authors asked database searchers whether they access BIOSIS for topics in psychology. The sample included psychology database searchers from an average of four institutions in higher education in each state and the District of Columbia. Out of 200 survey questionnaires, 130

${ }^{3}$ DIALOG Information Services, DIALOG Database Bluesheets (Palo Alto, Calif.: DIALOG Information Services, 1988).

\section{Book review editor needed for College \& Research Libraries}

The editor designate of College \& Research Libraries invites nominations and applications for the volunteer position of book review editor for College of Research Libraries. The book review editor will serve through the editor's three-year term. Applicants must be members of ALA and ACRL. Preferred qualifications include experience in academic libraries, evidence of editing activity, and a knowledge of the issues confronting academic libraries and their parent institutions. The value of the work to other academic librarians is the primary reward. However, the book review editor's institution may receive the monographs reviewed in exchange for partial secretarial and indirect expenses. The position offers excellent experience for someone seeking a future editorial assignment. Nominations and resumes, with names of three references, may be sent to: Gloriana St. Clair, Editor Designate, College d Research Libraries, Library Administration, Oregon State University, Kerr Library 121, Corvallis, OR 97331-4501; (503) 737-3411; fax, (503) 737-3453; Bitnet, STCLAIRG\%CCMAIL@UCS.ORST.EDU.BITNET. Applications received by March 15 will receive first consideration. were returned for a response rate of $65 \%$. A comments section afforded respondents an opportunity to explain their use or lack of use of BIOSIS. This data provided further insights into factors affecting BIOSIS Previews usage for topics in psychology.

The results of our survey indicated that $24 \%$ of our respondents had used BIOSIS for psychologyrelated topics, while $76 \%$ had not. However, several interesting observations were noted from the comments section. For example, online searchers use BIOSIS primarily for literature in animal behavior or where animals were designated as subjects. Research dealing with physiology, psychobiology, and neurotransmitters was also mentioned. Several respondents indicated that BIOSIS was informative in investigations on pharmaceuticals, effects of medications or drugs, as well as healthrelated issues. Interestingly, many respondents indicated that they were not aware that BIOSIS was a useful source for psychological topics.

Our data indicate that many psychology database searchers (over 75\%) many be unaware of the

\section{Letters}

\section{Leadership}

\section{To the Editor:}

Apropos of Richard M. Dougherty's letter in CむRL News (October 1989, p.799), may I comment for many librarians who have not found it possible to become active professionals? I happen to be a life member and was active before my retirement nine years ago. This is a luxury few can now afford.

Our first responsibility as a profession is to increase the salary scale of professional librarians. Secondly, we need to reduce the professional bureaucracy at the national level, and the proliferation of meetings. Thirdly, membership dues keep going up to where the average librarian cannot afford to join (other organizations compete for his or her membership dollars). Finally, put the cost of journal subscriptions at a level that the average librarian can afford.

Lower membership dues and less expensive journal subscriptions will attract more members, and future leaders, in our professional organizations. Only subsidized librarians can afford to attend national conferences that cost the individual between $\$ 500$ and $\$ 1,000$. I believe that most librarians would prefer a democratic ALA to one that appears to be elitist.-H. Vail Deale, Director of Libraries Emeritus, Beloit College. 
potential usefulness of BIOSIS as an adjunct to literature searching in the behavioral sciences. Although some respondents indicated they used BIOSIS for studies involving animal experiments, recent literature does suggest its usefulness to a wide range of applications in the field of psychology. However, the relatively higher cost of accessing BIOSIS in relation to other useful files, such as Medline or ERIC, may mitigate against its use.

The relatively low use of BIOSIS for psychology research may also be a reflection of the lack of marketing and availability of basic information on its potential usefulness to behavioral science librarians. Specialized workshops, professional publications, and commentary in BioSearch could be an effective method of promoting its value to researchers pursuing topics in psychology. BIOSIS would thus attain a higher visibility among endusers.

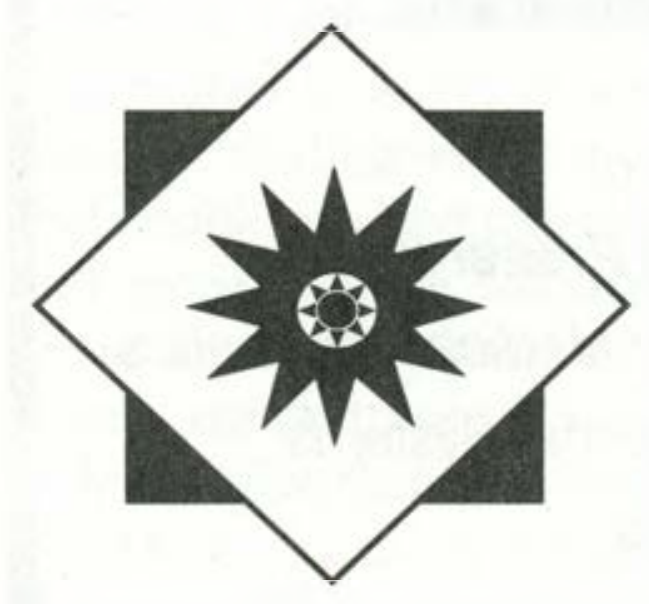

\title{
INNOVATIONS
}

\section{Humor and creativity: Library committees}

\author{
By Norman D. Stevens
}

Director

The Molesworth Institute

In my initial introduction to what has turned out to be a longer than anticipated series of short pieces on contemporary library humor and, to a lesser degree, creativity, I commented on some of the virtues of humor in the library workplace. One of those virtues, I suggested, was the extent to which the development of an inbred sense of humor among the members of the committees that so dominate the life of most academic libraries helped alleviate the tedium of committee work. Indeed one of my few and fondest recollections of serving as chair of the University of Connecticut Libraries' MRAP (Management Review and Analysis Program) Committee foisted off on us by ARL's newly established Office of Management Studies in the early 1970s is of the light-hearted approach to our work that safely carried us through to a successful conclusion. I am sure that I still have buried in my files somewhere the extensive list of alternative adjectives to express varying degrees of confidence in our conclusions that we developed as a handybut never applied — guide to the editing of our final report. Much, if not all, of that internal committee humor is so inbred that it makes little sense to outsiders even in the same library. Nor is most of it published or distributed very widely so it is among the scarcest kinds of library humor.

Not to worry. Committees have become so prevalent as a way of life in academic libraries and library associations and organizations that there is no lack of independent outside humor addressing the serious impact that committees have on our inability to get our real work done. Unfortunately few of us have either the power or the wisdom demonstrated by one of our best-known and bestbeloved college librarians who has firmly told his staff that he is available to attend committee meetings only before lunch. The widespread adoption of WAM's Law of Creativity-I hesitate to give him the full credit he is due for fear it will lead to censure by the ACRL Committee on Committees-would do more to increase productivity in academic libraries than any other step we might take. 